\title{
MSTER
}

\section{Interaction of an Iridium-Clad RTG Heat Source Unit with a Simulated Terrestrial Environment}

by
J. H. Patterson
B. Herrera
G. B. Nelson
G. M. Matlack
G. R. Waterbury

An Affirmotive Action/Equal Opportunity Employer 
Printed in the United States of America. Available from National Technical lnformation Strvice

U.S. Depaitment of Commerce

5285. Port Royal Road

Springfield, VA 22151

Price: Printed Copy \$3.50 Microfiche \$2.25

This repont was prepared as an account of work uponsored b. the Initer sivles Government. Neither the United Steten nor the ('nit minintratioti. nor ans of their employees, nor any of their conTraciors, Bubcantractors, of their employeti. makes any responsikility for the eceuracr. enmpletenets, or unefulnets af ont info tmation, apporalus, product, or proceso dicclosed, or repreasts that its une would not infrinter orivateiy owned 


\title{
INTERACTION OF AN IRIDIUM-CLAD RTG HEAT SOURCE UNIT WITH A SIMULATED TERRESTRIAL ENVIRONMENT
}

by

\author{
J. H. Patterson, B. Herrera, G. B. Nelson, \\ G. M. Matlack, and G. R. Waterbury
}

\begin{abstract}
An iridium-elad, $100-\mathrm{W}{ }^{238} \mathrm{PuO}_{2}$ sphere, a prototype for the multikundred-watt radioisotope thermoelectric generator, was exposed for 1 yr to a simulated temperate humid climete in an environmenta! test chamber containing sandy soil. The hot sphere sank into the soil after the first rain, then gradually acquired a hard crust around it as a result of the rainwater reacting with the hot soil during successive rains. Time and temperature profiles of the sphere were recorded during the weekly rains, and the air and rainwater that percolated through the soil were monitored for plutoniusn. No plutonium was released from the sphere. Aside from the crust formation, very little reaction occurred between the hot iridium shell and the soil.
\end{abstract}

\section{INTRODUCTION}

Radioisotope thermoelectric generators (RTGs) provide auxiliary electric power on many space missions. An RTG produces electric energy by a thermopile, whose hot junctions are heated by the decay of a radioactive isotope. Heat sources now used in RTGs for space applications contain pure plutonium oxide (PPO), which is prepared by the application of heat and pressure from purified plutonium dioxide powder that is $800^{\circ}$ enriched in $238 \mathrm{Pu}$. The heat sol'rces are then suitably packaged to prevent environmental contamination in case of an accident. As part of the packaging testing program, we subjected several fueled-sphere assemblies (FSAs) to a sequential safety test (SST) series that simulates the experience of FSAs during launch, reentry, and impact. ${ }^{~}$ The final test, after impact, was to expose one of the postimpact sphere assemblies (PISAs), a PPO sphere in its postimpact containment shel! (PICS), to environmental conditions in sandy soil for $1 \mathrm{vr}$.

An FSA is a basic fuel unit in the multihundredwatt (MHW) system that consists of a $37-\mathrm{mm}$-diam sphere of PPO that weighs $\sim 250 \mathrm{~g}$. The sphere is encapsulated in a verited PICS of $\sim 0.6-\mathrm{mm}$-thick iridium, which is, in turn, enclosed in a $12-\mathrm{mm}$-thick graphite impact sheil (GIS) of carbon-impregnated Thornel yain

\section{I. ENVIRONMENTAL EXPOSURE}

We used an environmental test chamber with a $1.8-\mathrm{m}^{3}$ working volume to study the release of $238 \mathrm{Pu}$ to the environment from an intact PISA after accidental land impact of a spacecraft with an RTG. The chamber was equipped with temperature and humidity controls to simulate a natural diurnal cycle. Rain was simulated by a spray from four heads that distributed the water evenly.

The impacted PISA (MHFT-27) was partially buried in $0.3-\mathrm{m}$-deep sandy soil (Table I) in a 0.9 - by $0.9-\mathrm{m}$ tray in the environmental chamber. This PISA had one superficial crack that apparently did not penetraie the shell. ${ }^{1}$ It was kept under humid conditions in the chamber for 373 days, of which 202 


\section{TABLE I}

\section{SOIL COMPOSITIONa}

Sand $(\%)$

89.6

Silt $(\%)$

Clay (\%)

Carbon, organic (\%)

Carbonate as $\mathrm{CaCO}_{3}(\%)$

$\mathrm{H}_{2} \mathrm{O}$ at 15 bars (\%)

$\mathrm{H}_{2} \mathrm{O}$ at saturation $(\mathrm{r} ;)$

$\mathrm{pH}$

Calcium (meq/100g)

Magnesium (meq/100 g)

Sodium (meq/100 g)

Potassium (meq/100 g)

Cation exch cap (meq/100 g)

Elect cond (mmho/cm)

Clay mineral ratio:

Montmorillonite

Kaolinite
22

9.1

17.8

1.7

0.9

0.5

6.0

0.6

5

3

a Analysis provided by the U.S. Soil Conservation Service Laboratory, Riverside, CA.

were under summer conclitions $\left(20\right.$ to $40^{\circ} \mathrm{C}, 87$ to $96 \% \mathrm{RH}$ ) and 171 were under winter conditions ( 0 to $17^{\circ} \mathrm{C}, 71$ to $100 \% \mathrm{RH}$ ). The PISA received $\sim 32 \mathrm{~mm}$ of rain weekly during the experiment. The water that percolated through the soil during and after each rain was collected for plutonium analysis. We measured the air concentration of plutonium by analyzing the water condensed from the air by the refrigeration-type dehumidifier in the chamber conditioning system. To obtain a depth profile of the plutonium, two pairs of $13-\mathrm{mm}$-diam soil cores, collected about every 6 months, were sectioned by horizontal cuts. Thermocouples welded to the top and bottom of the PISA continuously monitored the surface temperature, which was recorded using a Honeywell circular chart recorder.

During the first rain, the PISA, which had been placed with $60^{\circ} \%$ of its height above the surface of the soil, sank to a depth that left only $10 \%$ of its height exposed. We intentionally left the soil under the PISA very loose with large voids to avoid breaking the thermocouple welds during emplacement. Lubrication of the sand grains by the rain allowed the heavy PISA to sink into the loosely filled space. The surrounding soil may have been temporarily fluidized by the boiling of the rainwater by the hot PISA.

When most of the sphere was above the surface, the initial temperature of the PISA, as measured by the bottom thermocouple, was $620^{\circ} \mathrm{C}$. At the beginning of the first rain, the temperature dropped to $100^{\circ} \mathrm{C}$ in $5 \mathrm{~min}$, where it remained for $42 \mathrm{~h}$. It then began to rise, finally leveling off at $520^{\circ} \mathrm{C} 1$ wk after the rain. Evaporation of water in the surrounding soil seemed to be the mechanism that kept the PISA at $100^{\circ} \mathrm{C}$ for so long a time. After heating the water from 25 to $100^{\circ} \mathrm{C}$, the $100 \mathrm{~W}$ of thermal power from the PISA would probably evaporate about 6 liters of water in $42 \mathrm{~h}$. The temperature profile changed gradually to shorter lengths of time at $100^{\circ} \mathrm{C}$. Seven months later the PISA stayed at $100^{\circ} \mathrm{C}$ only during the rain. When the rain stopped, the temperature rose rapidly to $300^{\circ} \mathrm{C}$, then more slowly to the equilibrium temperature (Fig. 1). This indicated that a crust gradually formed and isolated the PISA from the water in the surrounding soil.

After the PISA sank into the soil during the first rain, the equilibrium temperature for tile bottom thermocouple was $520^{\circ} \mathrm{C}$, compared with $620^{\circ} \mathrm{C}$ before the rain. The temperature of the bottom thermocouple was also consistently lower than that of the top orie. The temperature differential range was 0 to $70^{\circ} \mathrm{C}$, and most often was less than $30^{\circ} \mathrm{C}$. The greatest difference occurred when the temperature started to rise from $100^{\circ} \mathrm{C}$, because the temperature of the top thermocouple started to rise before the bottom one. At higher temperatures, the top and bottom readings were often identical. These temperature trends indicate that there was good thermal conductivity between the top and bottom of the PISA, probably through the iridium shell, and

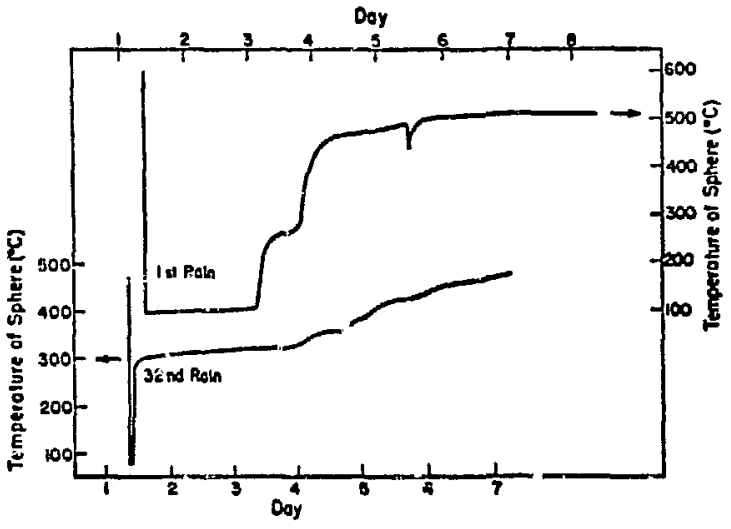

Fig. 1.

Temperature response of PISA (MHFT-27) to a rain sequence. 
that the heat was more efficiently removed by conduction to the soil than by convection and radiation in air. Radiation losses however would be greater in the open under clear skies.

Although the surface of the PISA had been previously contaminated by handling in a drybox that had been used with ${ }^{238} \mathrm{Pu}$, we found rery little plutonium in the water and soil samples from this experiment. Only 8 of 52 percolated rainwater samples and 6 of 74 dehumidifier condensate samples contained enough plutonium to be distinguishable from background. The tutal plutonium in these 14 samples was $0.23 \mu \mathrm{g}$. The soil cores contained even less plutonium. One core had $0.2 \mathrm{ng}$ of plutonium in each of its top two sectioi:3. We found no significant amount of plutonium in any of the other sections or cores. The plutonium found in this system undoubtedly came from the previous contamination of the PISA surface.

\section{TERMINATION OF THE EXPERIMENT}

After $1 \mathrm{yr}$ of exposure to this humid environment, we removed the PISA from the environmental chamber and found it almost completely encased in a 0.5 - to 3-cm-thick suil crust that could not be brcken manually without tools. This crust, apparently formed by the heat from the PISA baking the soil dry between rains, caused the change with time of the response of the surface temperature of the PISA to rain.

After its removal from the chamber, the PISA was cut open and the iridiun shell and its plutonium dioxide contents were examined." A bubble test revealed that both of the fritted vents for helium, located at opposite poles of the PIC'S, were closed. Metallographic and electron microprobe ex. aminations indicated that the vents were closed by a combination of vapor-deposited plutonium dioxide and a glassy phase consisting mostly of calcium, silicon, aluminum, and oxygen. Sintering of the frits also may have contributed to the plugging. These causes, common to closed vents in other PICS, probably happened before the PISA was exposed to the test environment. A plug, found at the mouth of the vent near the bottom of the PISA in the soil, contained the above elements plus phosphorus, which is not usually found in vents. The phosphorus may have been a product of irtteraction between the PISA and the soil. We found no evidence of water penetrating into the PICS or of attack on the iridium from inside or outside the PICS. A heavy coating of vapor coposited plutonium dioxide seemed to have been dislodged from its normal tight adherence to the inside of the PICS by the rapid thermal changes caused by the rains in the environmental chamber.

\section{CONCLUSIONS}

A PISA on, or just below, a sandy soil surface maintains a temperature beiow $650^{\circ} \mathrm{C}$. At the beginning of a rain, the surface temperature drops to $100^{\circ} \mathrm{C}$ in $5 \mathrm{~min}$. After 1 yr of temperate humid con. ditions, including a weekly $32-\mathrm{mm}$ rain, there is evidence of only a mild interaction beiween the PISA and its surroundings. There was no evidence of water perietrating into the PICS or of plutonium escaping from its containment. These results may be compared with those from allother experiment in which a PISA was buried $23 \mathrm{~cm}$ deep in dry soil for 67 days. 1 In that experiment, the PICS reached $1150^{\circ} \mathrm{C}$ and on recovery was found to have a thick coating of fused soil. In many places where the iridium was not protected by the fused soil, it was perforated by an erosive reaction with air and water vapor. Also, $0.02 \mathrm{~g}$ of plutonium dioxide was found in the fused soil.

\section{REFERENCES}

1. E. M. Cramer, "Performance of MultihundredWatt Fueled-Sphere Assemblies in the Safety Sequentizl Test Program," Los Alamos Scientific Laboratory report LA-5916 (July 1975).

2. E. M. Cramer, Los Alamos Scientific Laboratory, unpublished dat $\varepsilon, 1975$. 